\title{
Restoration of functional gait in paraplegic patients with the RGO-II hybrid orthosis. A multicentre controlled study. I. Clinical evaluation
}

\author{
P Thoumie ${ }^{1}$, B Perrouin-Verbe ${ }^{2}, \mathrm{G}$ Le Claire ${ }^{3}$, M Bedoiseau $^{1}$, M Busnel $^{3}$, A Cormerais $^{3}$, A Courtillon $^{4}$,

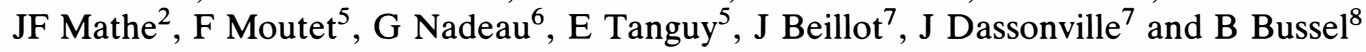 \\ ${ }^{1}$ SRF Groupe Hospitalier Bichat-Claude-Bernard, 16 Rue Henri Huchart, 75018 Paris; ${ }^{2}$ SRF, CHR Hopital \\ Saint-Jacques, 44035 Nantes; ${ }^{3}$ CRRF de Kerpape, 56321 Lorient; ${ }^{4} C R R F$ Rennes-Beaulieu, 35700 Rennes; \\ ${ }^{5}$ CRRF Pen-Bron, 44440 La Turballe; ${ }^{6}$ CRRF de l'Arche, 72650 Saint-Saturnin; ${ }^{7}$ Unité de Biologie et Médecine \\ du sport, Chu Ponchaillou, 35033 Rennes Cedex; ${ }^{8}$ INSERM U.215 SRF Hopital R Poincaré, 92 Garches, France
}

\begin{abstract}
By means of a multicentric study in six rehabilitation centres, we assessed the RGO-II orthosis to restore functional gait in patients with spinal cord injuries. The 26 subjects participating in the study had spastic complete paraplegia. Twenty one had progressed to the training programme and 19 were able to stand up alone. The trained subject's walking distance ranged from 200 to $1400 \mathrm{~m}$, while their walking speed ranged from 0.15 to $0.45 \mathrm{~m} \mathrm{~s}^{-1}$. A 2-month follow-up study revealed that, out of 15 patients using the hybrid orthosis, 11 were home users. Modalities and adverse effects of training are reported. The place of gait restoration with a hybrid orthosis in a rehabilitation programme is discussed.
\end{abstract}

Keywords: spinal cord injury; gait; orthosis; functional electrical stimulation

\section{Introduction}

Until recently, only paraplegic patients with an incomplete or low-level lesion were able to restore their gait in daily activities by using conventional leg braces. In the past 20 years, international studies have followed the development of more functional orthosis (hip guidance orthosis, reciprocating gait orthosis), in conjunction with functional electrical stimulation (FES).

Gait restoration in paraplegic people concerns not only psychological aspects and the functional contribution to daily activities but also the prevention of some common complications that can occur, for example: pressure sores, spasticity, osteoporosis and urinary tract infections.

Recent studies focused on the concept of a hybrid orthosis $^{1-4}$ which would combine the security and stability of a mechanical orthosis with the reduction of energy consumption due to FES when applied to paralysed muscles. The goal of this study was to evaluate the ability of the RGO-II orthosis ${ }^{1}$ to restore gait in paraplegic patients, and moreover to study its use in daily activities after the training programme. Training occurred between January 1992 and December 1993 in six rehabilitation centres and departments (part of the Association pour la Recherche sur la Marche Orthétique en Réadaptation (ARMOR) association), and the evaluation was performed in conjunction with the DELTA-7 association.

Correspondence: P Thoumie

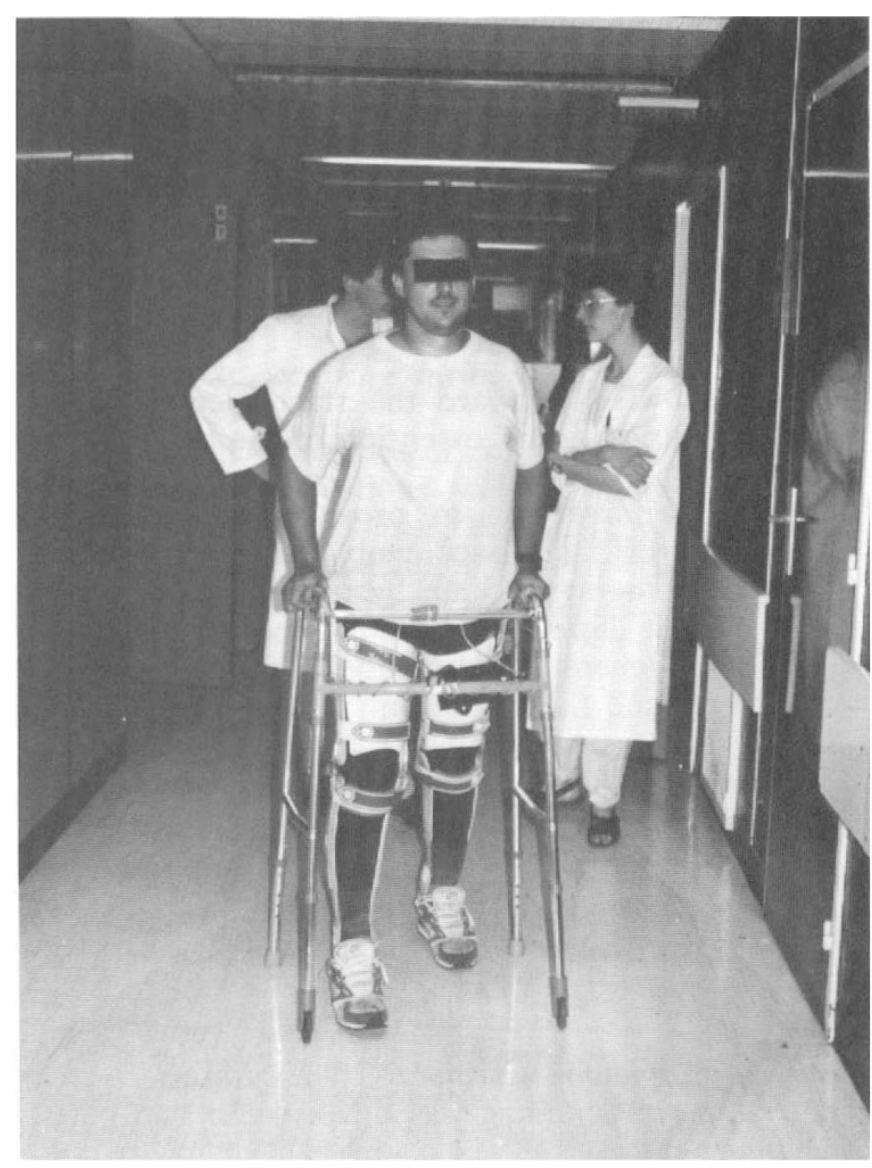

Figure 1 T5-level paraplegic patient fitted with an RGO-II orthosis 


\section{Subjects and methods}

Subjects

Twenty-six patients (three women and 23 men) were included in this study. The mean age of participants was 31 years (range: $20-53$ ), delay from the onset of the paraplegia was 32 months (range: 9-144). All of the patients fulfilled the selection criteria for the RGO-II orthosis: complete thoracic spastic paraplegia without hip, knee or foot contracture greater than $5^{\circ}$. Following the example of Phillips and Hendershot, ${ }^{3}$ we also included one patient with cervical lesion (C8), so that the levels of injury ranged from C8 to T11. All of the patients were informed of the purpose of the study, and they gave their consent with the understanding that they could stop training at any time without revoking their right to medical treatment.

\section{Equipment}

The RGO-II hybrid orthosis includes an RGO mechanical orthosis and an FES system which decreases energy consumption during locomotion. ${ }^{5}$

The LSU-RGO orthosis is a passive mechanical orthosis with specially designed hip joints connected to each other by two stainless steel cables. ${ }^{6}$ These cables prevent forward flexion of the trunk and provide force transmission from one hip to the other, thus making reciprocal movements of the legs possible. The FES system included a four-channel stimulator with pulses range from 0 to $150 \mathrm{~mA}$ and 0 to $120 \mathrm{~V}$ at a frequency of $20 \mathrm{~Hz}$, the pulse duration being $0.3 \mathrm{~ms}$. The stimulator's thumb switches are mounted on a rollator, so that pressing one switch will activate the quadriceps and the contralateral hamstring, thereby producing the swing phase and contralateral push-off.

To assume a forward step when using the RGO-II hybrid orthosis, the paraplegic patient follows this sequence of events:

1 Shift the weight toward the stance leg using the rollator support, and extension of the contralateral upper limb.

2 Use trunk extension to provide mechanical hip extension of the stance limb thus achieving hip flexion of the swing limb by transference of force through the hip cables. Simultaneous push-switch activation generates stimulation of the stance limb's hamstring and the swing limb's quadriceps muscles via the FES system.

3 Push the rollator forward to prepare for the next step.

Simultaneously pressing both switches produces active hip and knee extension which allows the patient to stand up without assistance.

\section{Training programme with the $R G O-I I$ orthosis}

The training programme was divided into two parts, each being at least 4-6 weeks long. During phase one, patients were fitted with the mechanical orthosis and were instructed to use it alone during gait training sessions. In the same part of the programme, electrical stimulation provided increased strength and resistance in the targeted leg muscles. During phase two, the patient in the RGO-II orthosis (with FES) was tested with various exercises (gait performance inside, outside, through doors) in order to make the study clinically practical.

\section{Protocol}

\section{Analysis of training data}

Each subject and physical therapist was instructed to pay attention to all parameters of the training programme: noting adverse effects, the duration of training programme, parameters of orthosis usage (doff and don times of the orthosis, standing with/without assistance, maximal walking distance during training sessions), parameters of home usage after training and reasons for stopping the programme.

\section{Gait parameters analysis}

Walking distance and biomechanical data

To avoid fatigue, gait evaluation was carried out over three sessions during 1 month.

In two separate sessions, the maximum walking distance achieved with the RGO alone and the RGO combined with FES was measured for all patients. The patients were asked to walk as far as possible at normal speed and to stop when they felt fatigued.

Gait analysis was performed for six patients by Locometre apparatus, a special device previously described by Bessou et al. ${ }^{7}$ Patients were all men, mean age: 35 years (range: 26-52), level of injury: T2-10, mean delay from paraplegia onset: 14 months (range 9-18). Each foot was linked by a thread to a lengthvoltage transducer, so that spatial and temporal components of gait for both legs could be recorded during several cycles in a walking session on normal ground. Gait parameters were measured during 1-min walking sessions under four experimental conditions: normal speed with/without FES and maximal speed with/ without FES. A 1-min rest period was observed between each test.

\section{Cardiovascular data}

Evaluation of cardiovascular parameters was performed during walking in four patients fitted with a mechanical and hybrid orthosis. Patients were all men, mean age: 31 years (range: 23-42), level of injury: T7-11, mean delay from onset of paraplegia: 30 months (range: 13-77). Each subject was trained to perform walking at different speeds of $0.1-0.4 \mathrm{~m} \mathrm{~s}^{-1}$. The experimental session included an initial $6 \mathrm{~min}$ walking session at $0.1 \mathrm{~m} \mathrm{~s}^{-1}$ to ensure stability, then progressed to 2 -min sessions with $1 \mathrm{~min}$ rest at increased speeds of $0.2 \mathrm{~m} \mathrm{~s}^{-1}, 0.3 \mathrm{~m} \mathrm{~s}^{-1}$ and $0.4 \mathrm{~m} \mathrm{~s}^{-1}$ until the subject was exhausted.

Heart rate, energy consumption and lactate rate were measured in each test.

Energy consumption $\mathrm{VO}_{2}$ study included gas collection in Douglas bags, volume analysis with Tissot bell 
and concentration analysis of $\mathrm{O}_{2}$ (OM 11, Beckman, USA) and $\mathrm{CO}_{2}$ (Rubis 3000, Cosma, France). Lactate rate was measured with microdosage using KontronLA 640 analyser after obtaining a sample of blood from the ear lobe.

\section{Statistical analysis}

We conducted statistical comparison between the values registered with and without FES using a variance analysis (ANOVA).

\section{Results}

\section{Training data}

Of the 26 subjects included in this study (Table 1), 21 subjects (one woman and 20 men) performed the whole training programme. Five subjects (two women and three men) discontinued their training for the following reasons:

- complications related to the paraplegia: syringomyelia in a man and a spontaneous fracture of both lower limbs in a woman;

- complications related to the training programme: pressure sores (at heel level in a woman and at the external malleolus in a man) and a spontaneous femoral crush occurring in a man during a training session.

The programme lasted 2-5 months for inpatients

Table 1 General data of the 26 patients included in the training programme

\begin{tabular}{|c|c|c|c|c|c|}
\hline Patient & Level & Sex & Age & $\begin{array}{c}S C I \\
\text { duration }\end{array}$ & $\begin{array}{c}\text { Training } \\
\text { success }\end{array}$ \\
\hline 1 & $\mathrm{C} 8$ & $\mathbf{M}$ & 31 & 24 & + \\
\hline 2 & $\mathrm{~T} 2$ & $\mathbf{M}$ & 35 & 24 & + \\
\hline 3 & $\mathrm{~T} 3$ & $\mathrm{~F}$ & 34 & 60 & + \\
\hline 4 & $\mathrm{~T} 3$ & $\mathbf{M}$ & 38 & 48 & - \\
\hline 5 & $\mathrm{~T} 4$ & $\mathrm{~F}$ & 33 & 26 & - \\
\hline 6 & T5 & $\mathbf{M}$ & 35 & 9 & + \\
\hline 7 & T6 & $\mathbf{M}$ & 44 & 24 & + \\
\hline 8 & T6 & $\mathbf{M}$ & 27 & 11 & + \\
\hline 9 & T6 & $\mathbf{M}$ & 26 & 36 & + \\
\hline 10 & T6 & $\mathbf{M}$ & 19 & 9 & + \\
\hline 11 & T6 & $\mathrm{F}$ & 40 & 48 & - \\
\hline 12 & T6 & $\mathrm{M}$ & 26 & 15 & + \\
\hline 13 & T6 & M & 52 & 24 & + \\
\hline 14 & $\mathrm{~T} 7$ & $\mathbf{M}$ & 29 & 36 & + \\
\hline 15 & $\mathrm{~T} 7$ & M & 28 & 24 & + \\
\hline 16 & T9 & $\mathbf{M}$ & 33 & 12 & + \\
\hline 17 & T9 & $\mathbf{M}$ & 20 & 24 & + \\
\hline 18 & T9 & $\mathrm{M}$ & 35 & 10 & - \\
\hline 19 & $\mathrm{~T} 10$ & $\mathrm{M}$ & 20 & 18 & + \\
\hline 20 & $\mathrm{~T} 10$ & $\mathrm{M}$ & 28 & 24 & + \\
\hline 21 & $\mathrm{~T} 10$ & M & 32 & 48 & + \\
\hline 22 & $\mathrm{~T} 10$ & $\mathbf{M}$ & 24 & 144 & -- \\
\hline 23 & $\mathrm{~T} 10$ & $\mathbf{M}$ & 33 & 20 & + \\
\hline 24 & $\mathrm{~T} 11$ & $\mathbf{M}$ & 24 & 12 & + \\
\hline 25 & $\mathrm{~T} 11$ & $\mathbf{M}$ & 24 & 36 & + \\
\hline 26 & $\mathrm{~T} 12$ & M & 43 & 72 & + \\
\hline
\end{tabular}

(17 patients, four centres) and 3-14 months for outpatients.

\section{Technical considerations}

Mechanical problems affected the orthotic hip and knee joints most commonly.

At hip level, locking was difficult for five subjects, and required recurrent changes. The knee joints rarely locked straight during standing after stimulation of both quadriceps; locking was usually performed before the stand-up manoeuver or with a special ratchet knee. ${ }^{1}$ Also, regular control of cable tension was necessary.

FES stimulation system failure occurred six times among the 25 subjects; five of these failures resulted from an electrical cable breakage at the end of the stimulator which required stronger solder.

\section{Difficulties in the training programme}

During the training programme, each team observed several common difficulties in their patients.

When using the RGO-II orthosis for walking, general 'fitness' was the most important factor in patient performance. Decline in physical condition, regardless of its origin, led to poor performance such that the effect of the hybrid orthosis remained insufficient to overcome fatigue in these patients.

Changes in muscular responses to stimulation, especially the diffusion of stimulation to synergist or antagonist muscles and flexion reflex, were observed daily.

The reliability of the whole system was problematic for half of the patients because minor failures necesitated a pause in the rehabilitation programme, producing a decrease in physical performance. This required reinforcement of upper limbs strength for these patients whose equilibrium control was compromised.

\section{Complications occurring during the rehabilitation programme}

Two different categories of complications were seen: intercurrent complications, which occurred during the programme but not during the training sessions and training-related complications which did occur during the training sessions.

Intercurrent complications These complications, which caused some subjects to abandon the programme, were the primary reason for increased programme duration. A spontaneous fracture of both lower limbs and the occurrence of syringomyelia comprised the intercurrent complications that resulted in programme abandonment. Temporary pauses in the programme were caused by non-specific complications of paraplegia (urinary tract infections), a spontaneous tibial fracture and a leg haematoma.

Training related complications Four types of complication occurred during the training sessions.

- In all but five patients, orthostatic hypotension occurred when electrical stimulation was applied 
during the upright posture in the first session. It disappeared soon after stimulation stopped and did not occur again. None of the patients discontinued training for this reason.

- Pressure sores occurring at foot and ankle level induced a definitive gap in two patients' training programme. Two low grade pressure sores of the toe and sacrum affected two other patients but did not delay the training programme.

- No burns from the electrical stimulation were observed, except for two areas of erythema produced by the electrodes. They disappeared in less than $24 \mathrm{~h}$.

- A spontaneous fracture of the tibia occurred during one training session and resulted in an isolated increase of knee size. Healing was successful in this patient after 4 months, but the training programme was discontinued.

Fractures of lower limbs As previously described, four bone fractures occurred in three patients: one man and two women, age: 24,28 and 40 years; level of injury: T5, T6 and T10; delay of paraplegia onset: 4, 5 and 12 years. Only one fracture occurred during a training session, the three others occurred spontaneously during daytime activities. Bone mineral density of the femoral neck was measured in two of them with dual biphotonic absorptiometry and corresponded to $-30 \%$ and $-34 \%$ of normal value.

\section{Orthosis-use parameters at the end of training programme}

Table 2 shows the data from 21 patients who successfully completed the training programme.

Table 2 Follow-up of RGO-II orthosis usage at the end of the training programme $(n=21)$

\begin{tabular}{rcccl}
\hline Patient & Level & $\begin{array}{c}\text { Duration } \\
\text { (months) }\end{array}$ & $\begin{array}{c}\text { Frequency } \\
(\text { month) }\end{array}$ & $\begin{array}{l}\text { Mode } \\
\text { utilisation }\end{array}$ \\
\hline 1 & C8 & $>2$ & 4 & RGOII/FES \\
2 & T2 & $>2$ & 8 & RGOII \\
3 & T3 & $>2$ & 3 & RGOII \\
6 & T5 & 0 & 0 & \\
7 & T6 & $>2$ & 8 & RGO \\
8 & T6 & $>2$ & 8 & RGOII \\
9 & T6 & 1 & 4 & RGOII \\
10 & T6 & 1 & 4 & RGOII \\
12 & T6 & $>2$ & 18 & RGO \\
13 & T6 & $>2$ & 15 & RGOII \\
14 & T7 & $>2$ & 12 & RGOII \\
15 & T7 & $>2$ & 8 & RGOII \\
16 & T9 & $>2$ & 8 & RGOII \\
17 & T9 & 2 & 8 & FES \\
19 & T10 & $>2$ & 12 & RGO \\
20 & T10 & 1 & 6 & RGOII \\
21 & T10 & $>2$ & 4 & RGOII \\
23 & T10 & $>2$ & 20 & RGOII \\
24 & T11 & $>2$ & 12 & RGOII \\
25 & T11 & 0 & 0 & \\
26 & T12 & $>2$ & 12 & RGO \\
\hline
\end{tabular}

Six patients discontinued using the orthosis within the following 2 months. Four of them were inpatients who did not wish to use the orthosis at home, one was an outpatient who changed residence, and one other outpatient switched his job. All of these patients experienced technical difficulties with the orthosis.

Mean usage frequency was eight times per month (range: 0-20) during the 2 months following the training programme.

\section{Gait parameter evaluation}

Walking distance and biomechanical parameters

The maximal walking distance values during the training sessions (all patients) were $200-1400 \mathrm{~m}$ with FES and 150-400 $\mathrm{m}$ without FES.

Table 3 shows gait parameter data registered with the Locometre apparatus in six of these patients under four experimental conditions. No significant changes in gait parameters were shown when patients used the mechanical or hybrid orthosis at their preferred walking speed (mean value: $0.20 \pm 0.02 \mathrm{~m} \mathrm{~s}^{-1}$; range: $\left.0.15-0.28 \mathrm{~m} \mathrm{~s}^{-1}\right)$. With the mechanical orthosis only, a higher speed $\left(0.29 \pm 0.03 \mathrm{~m} \mathrm{~s}^{-1} ;\right.$ range $\left.0.22-0.41 \mathrm{~m} \mathrm{~s}^{-1}\right)$ resulted in reduced stance duration $(2.49 \pm 0.5 \mathrm{~s}$ vs $3.01 \pm 0.4 \mathrm{~s})$ and an increased step length $(0.83 \pm 0.13 \mathrm{~m}$ vs $0.72 \pm 0.14 \mathrm{~m})$ whilst swing duration remained similar $(0.47 \pm 0.05 \mathrm{~s}$ vs $0.46 \pm$ $0.06 \mathrm{~s})$. During maximal speed walking with the hybrid orthosis, the results were not significantly higher $\left(0.32 \pm 0.02 \mathrm{~m} \mathrm{~s}^{-1}\right.$; range: $\left.0.21-0.45 \mathrm{~m} \mathrm{~s}^{-1}\right)$ compared to the maximal speed achieved with the mechanical orthosis alone.

Thus, in this small group of patients, there seemed to be a greater endurance/walking distance.

\section{Cardiovascular parameters}

This was studied in four subjects. FES did not induce changes in maximal speed: the mean value in four subjects was $0.33 \pm 0.05 \mathrm{~m} \mathrm{~s}^{-1}$ with FES and $0.33 \pm$ $0.12 \mathrm{~m} \mathrm{~s}^{-1}$ without FES. At this maximal speed, FES use induced a tendency to decreased heart rate $(165 \pm 14$ vs $175 \pm 11 \mathrm{bpm})$ and decreased lactate rate $\left(4.25 \pm 1.4\right.$ vs $\left.4.75 \pm 0.82 \mathrm{mmol} \mathrm{ml}^{-1}\right)$, but these changes were not significant. FES usage was related to a significantly increased oxygen consumption when patients were walking at maximal speed $(19.4 \pm 3.05 \mathrm{vs}$ $\left.15.6 \pm 1.43 \mathrm{ml} \mathrm{mn}^{-1} \mathrm{~kg}^{-1} ; \mathrm{F}=11.42, P<0.05\right)$.

\section{Follow-up study}

Fifteen patients (one woman and 14 men) used the orthosis for more than 2 months. Four of these patients used the orthosis only in the hospital or the rehabilitation centre for training sessions.

Some considerations concerning the use of hybrid orthosis in daily life may be pointed out (Table 4). Four patients only used the mechanical orthosis because they did not believe that using FES gave them any advantage. Finally, two patients used the FES between gait sessions because it had a beneficial effect on their spasticity. 
Table 3 Locometre gait analysis data $(n=6)$

\begin{tabular}{|c|c|c|c|c|c|}
\hline & \multicolumn{4}{|c|}{ Six paraplegic patients } & \multirow{2}{*}{$\begin{array}{c}\text { Control } \\
\text { data } \\
\text { (from Bessou) }\end{array}$} \\
\hline & $\begin{array}{l}\text { Freed speed } \\
\text { mechanical } \\
\text { orthosis }\end{array}$ & $\begin{array}{c}\text { Freed speed } \\
\text { Hybrid } \\
\text { orthosis }\end{array}$ & $\begin{array}{l}\text { High speed } \\
\text { mechanical } \\
\text { orthosis }\end{array}$ & $\begin{array}{c}\text { High speed } \\
\text { hybrid } \\
\text { orthosis }\end{array}$ & \\
\hline Walking speed $\mathrm{ms}^{-1}$ & $0.21 \pm 0.02$ & $0.20 \pm 0.02$ & $0.29 \pm 0.03$ & $0.32 \pm 0.02$ & $1.58 \pm 0.14$ \\
\hline Cycle duration (s) & $3.48 \pm 0.53$ & $3.57 \pm 0.51$ & $2.95 \pm 0.5$ & $2.91 \pm 0.47$ & $0.98 \pm 0.05$ \\
\hline Double support duration (s) & $1.27 \pm 0.25$ & $1.33 \pm 0.25$ & $1.01 \pm 0.2$ & $0.96 \pm 0.15$ & $0.09 \pm 0.02$ \\
\hline Stance duration (s) & $3.01 \pm 0.4$ & $3.11 \pm 0.5$ & $2.49 \pm 0.5$ & $2.43 \pm 0.3$ & $0.59 \pm 0.04$ \\
\hline Swing duration (s) & $0.47 \pm 0.05$ & $0.46 \pm 0.07$ & $0.46 \pm 0.06$ & $0.48 \pm 0.05$ & $0.39 \pm 0.02$ \\
\hline Swing speed $\left(\mathrm{m} \mathrm{s}^{-1}\right)$ & $1.53 \pm 0.21$ & $1.54 \pm 0.20$ & $1.8 \pm 0.25$ & $1.94 \pm 0.21$ & $3.91 \pm 0.29$ \\
\hline Step length (m) & $0.72 \pm 0.14$ & $0.72 \pm 0.13$ & $0.83 \pm 0.13$ & $0.91 \pm 0.12$ & $0.78 \pm 0.08$ \\
\hline
\end{tabular}

Table 4 Parameters of RGO-II orthosis usage 2 months after the end of the training programme $(n=15)$

\begin{tabular}{rrlrc}
\hline Patient & Level & $\begin{array}{l}\text { Standing } \\
\text { up }\end{array}$ & $\begin{array}{c}\text { Walking } \\
\text { range }\end{array}$ & $\begin{array}{c}\text { Application } \\
\text { duration }\end{array}$ \\
\hline 1 & C8 & With help & $30 \mathrm{~m}$ & $10 \mathrm{~min}+$ \\
2 & T2 & Alone & $1000 \mathrm{~m}$ & $15 \mathrm{~min}$ \\
3 & T3 & With help & $60 \mathrm{~m}$ & $10 \mathrm{~min}+$ \\
7 & T6 & Alone & $350 \mathrm{~m}$ & $10 \mathrm{~min}$ \\
8 & T6 & Alone & $300 \mathrm{~m}$ & $10 \mathrm{~min}$ \\
12 & T6 & Alone & $300 \mathrm{~m}$ & $8 \mathrm{~min}$ \\
13 & T6 & Alone & $500 \mathrm{~m}$ & $15 \mathrm{~min}$ \\
14 & T7 & Alone & $100 \mathrm{~m}$ & $15 \mathrm{~min}$ \\
15 & T7 & Alone & $1200 \mathrm{~m}$ & $10 \mathrm{~min}$ \\
16 & T9 & Alone & $1000 \mathrm{~m}$ & $10 \mathrm{~min}$ \\
19 & T10 & Alone & $500 \mathrm{~m}$ & $15 \mathrm{~min}$ \\
21 & T10 & Alone & $100 \mathrm{~m}$ & $5 \mathrm{~min}$ \\
23 & T10 & Alone & $800 \mathrm{~m}$ & $10 \mathrm{~min}$ \\
24 & T11 & Alone & $300 \mathrm{~m}$ & $15 \mathrm{~min}$ \\
26 & T12 & Alone & $30 \mathrm{~m}$ & $10 \mathrm{~min}$ \\
\hline
\end{tabular}

+ : With help

The time needed to apply and take off the entire system ranged from 5 to $15 \mathrm{~min}$. Nineteen subjects out of 21 could successfully stand up alone. The common walking range was 30-1200 m, unrelated to the neurological level with the exception of one patient with a cervical lesion, who performed the smallest distance. Additionally, two patients successfully entered a car with the orthosis.

\section{Discussion}

The RGO-II hybrid orthosis was developed to enable complete spastic thoracic paraplegic patients to stand up and walk with lower energy consumption than with other orthoses.

\section{Analysis of results}

Our study confirmed that the training programme can be performed by all subjects who fulfil the selection criteria. During the initial phase, only a few well known complications related to patient fragility and occurring during or between the training sessions, prevented the programme from continuing. One tetraplegic patient even succeeded in walking with the hybrid orthosis, although his results were worse than those achieved by subjects who had paraplegia. The patient put on the orthosis and stood up with help, and the maximal walking range was limited to $150 \mathrm{~m}$ during training sessions and $30 \mathrm{~m}$ at home.

Maximal walking range values spread from 200 to 1400 meters in all of the patients during training sessions, depending on the subject's performance and unrelated to the neurological level. The higher values correspond to those previously reported by others authors. ${ }^{1}$ Nevertheless in this study, lower values $(30-1200 \mathrm{~m})$ have been observed for daily usage tasks such as household activities.

Our study does not suggest direct arguments for the concept that FES decreases energy expenditure in upper limbs, ${ }^{5}$ since decrease in heart rate and lactate blood rate are not significant. An increased overall oxygen consumption is observed in our subjects and may correspond to the additional energy consumed by the stimulated muscles. ${ }^{8}$ Indirect arguments for a reduced energy consumption in the upper limbs are the increased walking distance related with FES use.

As was previously described, ${ }^{4}$ FES use did not induce a significant change in the gait parameters and the speed remained low, at one fifth of normal speed. These non-significant changes in physiological and biomechanical parameters when registered on short distances explain why, during household activities, some subjects kept walking with their mechanical orthosis alone and did not feel that FES offered any benefit for them.

Major difficulties in the rehabilitation programme related to mechanical hip and knee joint adjustments as well as to the fragility of electrical connections. Even when the RGO-II hybrid orthosis performance corresponded to previously reported results, its daily use required strict maintenance by the rehabilitation team, as slowing down the programme would have resulted in a loss in function in both the upper and lower limbs. Although the use of the hybrid orthosis may be of value in and around the rehabilitation centre, its usage may be a problem for patients elsewhere. 
In terms of post-training daily activities, several types of usage eventually became obvious for the patients.

- Four patients continued to use the RGO-II hybrid orthosis in 'protected areas', ie the rehabilitation centre. These 'exercise walkers' used their orthoses up to 20 times a month for physical exercise. Similarly, some patients only used FES for its beneficial effect on trophicity and spasticity.

- Eleven patients-community walkers-used their orthoses at home. However, they only used it in and around the home. None reported walking with their orthosis whilst at work, and only two attempted to use their orthoses after entering a car.

- Six patients stopped using their orthoses as soon as they returned home and did so because they had changed their daily activities, were reluctant to use the orthosis in social activities, and/or had difficulty in assuming maintenance responsibilities for the orthosis, as is usually observed with common long leg braces.

When comparing our results to data reported in other studies, it was difficult to assess the effectiveness of the RGO-II hybrid orthosis because so few patients have been fitted with a similar orthosis.

Whittle $e t a l^{9}$ compared RGO and HGO usage in 22 subjects, two of whom failed to complete training, and four who did not continue walking with the orthosis after the training sessions. Since three women out of four did not continue walking, physiological and psychological reasons for discontinuing usage may apply.

In our study, some limiting factors for daily usage of the RGO-II orthosis were observed.

- Gait speed remains low, close to $0.2 \mathrm{~m} \mathrm{~s}^{-1}$ in normal use, corresponding to one fifth of the gait speed achieved by a healthy person $\left(1.58 \mathrm{~m} \mathrm{~s}^{-1}\right)$.

- Control of equilibrium required both a walking frame and visual control. In terms of self-sufficiency, the necessity of using both hands to manage equilibrium and propulsion decreased the advantages of such a system.

- Gait parameters under training conditions cannot be applied to household conditions. That is, daily performance at home was significantly lower than the parameters registered in the protected area. This finding suggests that other factors (psychological or sociological) need to be taken into account regarding the evaluation of orthosis usage. This point will be developed in a separate study. ${ }^{10}$

\section{Perspectives}

The number of paraplegic patients who could benefit from the gait system was evaluated by Jaeger et $a l^{11}$ from inconclusive criteria such as age (18-50 years), injury level (T4-12), absence of upper limb involvement and medical contraindication (cardiovascular disease or osteoporosis). Judging from these limited clinical parameters, only $11-25 \%$ of those with complete paraplegia (estimated percentage in a 192-sub- jects study) may benefit from such a system; this estimate includes $5-11 \%$ of all spinal cord injured patients.

Applying such an optimistic hypothesis, $(25 \%$ of complete paraplegic patients ie $11 \%$ of all spinal injured patients may be included in the training programme), only 11 of the 25 patients in our study will retain use of their orthoses after 2 months of household use; this would correspond to $11 \%$ of complete paraplegic subjects, ie only $5 \%$ of the total paraplegic population. A similar evaluation was made recently in a consensus conference on this subject. ${ }^{12}$

The meagre use of this orthosis after the detailed training programme we provided supports our critical observation that an experimental team must assume maintenance responsibilities in terms of the medical survey, and the orthotic and rehabilitation programme. Whittle $e t a l^{9}$ also previously documented these limiting factors. A prolonged relationship between the patient and the rehabilitation team is necessary to achieve long term usage of the RGO-II hybrid orthosis; however, considering its current status, the orthosis' limiting factors make it viable only for use in established rehabilitation centres.

Other questions concern limiting factors that require to be considered before including patients in a gait restoration programme. Should we exclude patients with severe osteoporosis? Which threshold may be considered? This would prevent the increased risk of fracture. Should we consider that such patients are good candidates for rehabilitation as a unique way to expect bone loss restoration? Further studies should assess the 'gain' of rehabilitation by comparing physiological benefits to possible adverse effects.

\section{Acknowledgements}

Special thanks are extended to the patients who consented to participate in this study, the orthotic technicians and the physical therapists from rehabilitation teams taking part in ARMOR association. Ours thanks are also due to Professor Moshe Solomonow, Drs R Baratta and E Aguilar for technical assistance and Noelle Ponthieu for improving the English. This work was supported by a grant from DELT A-7 association.

\section{References}

1 Solomonow $\mathrm{M}$ et al. The RGO generation II: Muscle stimulation powered orthosis as a practical walking system for thoracic paraplegics. Orthopedics 1989; 12: 1309-1315.

2 Isakov E, Douglas R, Berns P. Ambulating using the reciprocating gait orthosis and functional electrical stimulation. Paraplegia 1992; 30: 239-245.

3 Phillips CA, Hendershot DM. Functional electrical stimulation and reciprocating gait orthosis for ambulation in a tetraplegic patient: a case study. Paraplegia 1991; 29: 268-276.

4 Nene AV, Patrick JH. Energy cost of paraplegic locomotion using the Parawalker-electrical stimulation hybrid orthosis. Arch Phys Med Rehabil 1990; 71: 116-120.

5 Hirokawa $\mathrm{S}$ et al. Energy consumption in paraplegic ambulation using the reciprocating gait orthosis and electric stimulation of the thigh muscles. Arch Phys Med Rehabil 1990; 71: 687-694.

6 Douglas R, Larson PF, D'Amdrosia R, McCall RE. LSU 
reciprocating gait orthosis. Orthopedics 1983; 6: 843-838.

7 Bessou P, Dupui P, Montoya R, Pages B. Simultaneous recording of longitudinal displacements of both feet during human walking. J Physiol (Paris) 1988; 83: 102-110.

8 Pollack $\mathrm{F}$ et al. Aerobic training effects of electrically induced lower extremity exercises in spinal cord injured people. Arch Phys Med Rehabil 1989; 70: 214-219.

9 Whittle MW et al. A comparative trial of two walking systems for paralysed people. Paraplegia 1991; 29: 97-102.
10 Morvan JB et al. Psychosocial evaluation of orthotically aided walking in paraplegics Project CTENRHI-Delta-7. (Submitted for publication).

11 Jaeger RJ, Yarkony GM, Roth EJ, Lowell L. Estimating the user population of a single electrical stimulation system for standing. Paraplegia 1990; 28: 505-511.

12 Kantor C et al. Report on a conference on motor prostheses for workplace mobility of paraplegics patients in North America. Paraplegia 1993; 31: 439-456. 